\title{
Indian adolescents' perceptions of the home food environment
}

\author{
Neha Rathi ${ }^{*}$, Lynn Riddell and Anthony Worsley
}

\begin{abstract}
Background: The home food environment has the potential to influence the eating behaviour of adolescents. This investigation aimed to understand Indian adolescents' perspectives of their home food environments.

Methods: Adolescents aged 14-16 years ( $n=1026,65.3 \%$ girls) attending private secondary schools in Kolkata completed a paper-based questionnaire during school time which included questions about family food rules, availability and accessibility of foods at home, and domestic cooking responsibility. Boys' and girls' opinions and experiences were compared through cross-tabulation analyses.

Results: Almost all the adolescents reported that fruits (91.6\%) and vegetables (95.7\%) were always available in their homes. Approximately two-fifths reported that sugar-sweetened beverages (36.2\%) and salty snack foods (38.0\%) were readily available. In $56.1 \%$ households, adolescents were expected to follow certain food rules during mealtimes (e.g. not talking with my mouth full). The majority of the respondents (80.4\%) identified mothers as the primary meal providers, only a minority reported that fathers $(5.1 \%)$ were responsible for preparation of family meals.

Conclusion: This understanding of the family-environmental determinants of adolescent dietary habits provides useful directions for nutrition promotion interventions. Health and educational professionals associated with adolescents could communicate about the development of healthy home food environments to provide positive health benefits for adolescents and their families.
\end{abstract}

Keywords: Home food environment, Adolescents, India

\section{Background}

The rapid emergence of adolescent obesity in India over the last decade $[1,2]$ has led to increasing concern about the diets of adolescents [3]. India adolescents' diets appear to be characterised by over-consumption of energy-dense, nutrient-poor foods and sugar-sweetened beverages as well as low intakes of fruits and vegetables $[4,5]$. These poor dietary intakes can have a significant impact on both immediate and long-term health of adolescents [6].

A healthy diet can substantially reduce the risk of obesity and obesity-related morbidities, such as diabetes, hypertension, a range of carcinomas and coronary disease [3]. For adolescents, a healthy diet also contributes to physiological growth and development [7]. Since food habits adopted during adolescents are likely to be maintained during adulthood [8], it is important to

\footnotetext{
* Correspondence: nrathi@deakin.edu.au

Institute for Physical Activity and Nutrition, Deakin University, Geelong, VIC, Australia
}

(c) The Author(s). 2018 Open Access This article is distributed under the terms of the Creative Commons Attribution 4.0 International License (http://creativecommons.org/licenses/by/4.0/), which permits unrestricted use, distribution, and reproduction in any medium, provided you give appropriate credit to the original author(s) and the source, provide a link to the Creative Commons license, and indicate if changes were made. The Creative Commons Public Domain Dedication waiver (http://creativecommons.org/publicdomain/zero/1.0/) applies to the data made available in this article, unless otherwise stated. assist in development of successful interventions to address adolescent obesity [9].

Several factors appear to influence the development of adolescent dietary practices. These include individual (e.g. taste, nutrition-related knowledge, self-efficacy) social environmental (e.g. parents, peers), physical environmental (e.g. school canteen, fast food establishments), and macrosystem influences (e.g. food advertisements) [9-13].

Empirical evidence clearly highlights the importance of parents and home environment as a key component of healthy adolescent development [14-16]. During adolescence, parents continue to function as primary food gatekeepers for their families [11, 13]. Adolescents meet about two-fifths of their daily nutritional needs from foods available at home [17]. In addition, data from developed countries like the US [18] and New Zealand [19] suggest that $30 \%-42 \%$ adolescents consume one family meal daily at home. Moreover, Neumark-Sztainer and colleagues 
reported that nearly three-quarters of adolescents $(n=$ 252) enjoyed eating meals at home in the company of their family members [18] highlighting, the significance of home environment in adolescent nutrition.

Food-related parenting practices [20], parental role modelling [21], provision of food within the home environment [22], and eating meals as a family [23] have been recognised in Western countries as powerful predictors of food consumption among adolescents. For example, the availability of unhealthy savoury snacks at home may be associated with increased intake among adolescents [22]. Similarly, the opportunity for adolescents to eat meals with their families has been associated with healthy eating attitudes and behaviours [23, 24]. Authoritarian feeding styles (in which parents compel adolescents to consume certain foods or complete meals) have been associated with lower intake of nutritious foods [20] but high consumption of energy-dense, nutrient-poor snacks [25] and greater weight gain [26] in young people.

While the evidence regarding adolescents' home food environments is expanding, the majority of research to date has been conducted in economically developed countries. There is currently a paucity of literature examining parental influence and home food environments in the Indian context. To our knowledge, only one qualitative study has explored the influences on Indian adolescents' dietary behaviours [27]. Parental and peer influences, home and school food environments, as well as mass media emerged as key perceived influences on adolescent dietary behaviours [27]. Therefore, the aim of this study is to better understand Indian adolescents' home food environments using quantitative techniques within a broad sample of adolescents. Evidence suggests that there are gender-based differences in young people's attitudes towards health and food-related issues, females tending to exhibit healthier attitudes and dietary habits than males $[28,29]$. Therefore, based on this evidence it is important to evaluate gender differences on the household environment variables.

\section{Methods}

\section{Study design and sampling}

The present investigation draws on cross-sectional data from a sample of 1026 Indian adolescents who participated in the "Dietary and Lifestyle" (DAL) survey. DAL survey details have been reported previously [30-32], and are also outlined below. The survey protocol received ethical approval from Deakin University's Health Ethics Advisory Group (HEAG-H 187_2014).

The sampling frame for this investigation consisted of year nine students (aged 14-16 years) studying in English-speaking, private secondary schools in Kolkata, India. Through convenience sampling, private secondary schools $(n=9$; two co-educational schools, two single- sex boys' schools, and five single-sex girls' schools) were selected because obesity is more prevalent among private school students when compared to government school students [33]. Moreover, private schools are responsible for delivering secondary education to $40 \%$ adolescents in urban India [34].

\section{Survey instrument}

The students were asked to complete the Dietary and Lifestyle Questionnaire (DALQ) during school hours. This 15-page, self-reported instrument included a number of measures $(n=17)$ of the home food environment which were developed after a review of the literature [18, 22, 35, $36]$ and 52 face-to-face interviews with adolescents, parents, teachers and school principals [27]. Five statements were used to elicit adolescents' perceptions of family food rules. Two questions asked about food accessibility at home and seven items enquired about the availability of food at home. Three items relating to domestic cooking responsibility were also listed in the DALQ. All these items used four-point response scales ranging from "never" (1), "sometimes" (2), "usually" (3), and "always" (4). In addition, three items relating to the students' age, gender, and religion were included. Categorical responses were used for these demographic measures. For example, the question about the ages of the respondents had three response categories: "14 years" (1), "15 years" (2), and "16 years" (3). Prior to conducting the full-scale survey, the survey measures were pre-tested among a convenience sample of 47 adolescents to ensure their clarity. This was followed by the reliability study where 37 adolescents completed the survey twice with a test-retest interval of four weeks. The correlation coefficient $(r)$ values for the test-retest reliability of the 17 home food environment measures discussed in the present context are indicated in Table 1.

\section{Procedure}

A detailed explanation of the survey methods was presented to the school authorities in person. During morning assemblies, the school authorities made announcements to invite all year nine students $(n=1095)$ to complete the survey. A recruitment pack was sent to students' homes for parental approval. In total, 1079 parents provided written consent for their adolescent's participation. Subsequently, 1026 students completed the survey in the presence of teachers and the researcher on school premises between December 2015 and April 2016 (i.e. response rate 93.6\% of adolescents invited to take part). This sample size assured adequate power for the study (i.e. a power of 97\%), an effect size of 0.3 (Cohen's $d$ ), and a significance level of .01. The respondents did not receive any gifts or incentives for their participation. 
Table 1 Correlation coefficient ( $r$ ) values for test-retest reliability of home food environment measures ${ }^{a}$

\begin{tabular}{ll}
\hline Measure & $r$ (Pearson's \\
& correlation) \\
\hline Family food rules & 0.85 \\
I'm allowed to buy whatever I want from fast & 0.87 \\
food joints & 0.79 \\
I can eat whatever I like at home & 0.89 \\
During meal times, I'm allowed to put the TV on & \\
I'm expected to eat all the foods served even if I & 0.91 \\
don't like them & \\
At mealtimes I have to follow certain rules & 0.84 \\
Accessibility to food at home & 0.58 \\
Vegetables are served at dinner & \\
There is plenty of food at home & 0.64 \\
Availability of food at home & 0.82 \\
Potato chips or other salty snack foods & 0.88 \\
Soft drink (e.g. Coke) & 0.71 \\
Chocolate or other lollies (sweets) & 0.92 \\
Cakes/pastries/donuts/biscuits & 0.72 \\
Fruits & 0.76 \\
Vegetables & \\
Fruit juice & 0.35 \\
Momestic cooking responsibility & \\
My father makes all the food at home & \\
\hline
\end{tabular}

${ }^{a}$ All the correlations except for the last item i.e. "My father makes all the food at home" were statistically significant at $p<0.01$

\section{Data analysis}

After examining for completeness and consistency, the questionnaire data was entered into the Statistical package for Social Sciences (SPSS version 22.0, IBM Corp., Armonk, NY, 2013) which was used for data analyses. Descriptive statistics were calculated to summarise the variables. After inspection of the data the four pointresponse scales were merged to form two categories 'never/sometimes' and 'usually/always' for crosstabulations. Cross-tabulations were used to evaluate gender differences on the environment variables. Statistical significance was set at $p$-value $<.01$.

\section{Results}

\section{Demographic characteristics}

Nearly, two-thirds of the adolescents (65.3\%) were girls, the majority of the sample was aged between 14 and 15 years $(86.1 \%)$, with the remainder $(13.9 \%)$ reporting their age as 16 years. Hinduism (70.7\%) was identified as the most common religion.

\section{Family food rules}

Approximately three fifth of the participants (58.8\%) stated that they were allowed to eat foods of their choice at home (Table 2). In $56 \%$ of homes, adolescents were required to adhere to certain food rules during the course of their meals (e.g. not talking with my mouth full). However, nearly two thirds of the adolescents (64.6\%) reported that they did not have a family food rule prohibiting television viewing during meal times. On the whole, the cross-tabulation analyses indicate that the prevalence of family meal time rules did not significantly vary between boys' and girls' homes. Nonetheless, a significantly higher proportion of boys (59.3\%) than girls $(48.7 \%)$ reported that they were expected to eat all the foods served even if they did not like them $(p<.01)$.

\section{Accessibility of food at home}

In the majority of the households (83.3\%), an adequate amount of food was available all the time (Table 2). Around three fourth of the participants (76.7\%) revealed that vegetables were regularly served at dinner. Both the male and female respondents had similar views of food accessibility.

\section{Availability of food at home}

Fruits (91.6\%) and vegetables (95.7\%) were the most frequently available foods in students' homes (Table 2). Salty snack foods like potato chips (38.0\%) and soft drink (36.2\%) were the least regularly available food items in homes. The cross-tabulation analyses indicated that the availability of various food items did not significantly vary in the homes of boys compared to the homes of girls. Nonetheless, more boys (43.0\%) than girls $(32.5 \%)$ indicated that sugar-sweetened beverages were available at home $(p<.01)$.

\section{Domestic cooking responsibility}

The individuals most likely to be responsible for household meal preparation were the adolescents' mothers $(80.4 \%)$ whereas fathers $(5.1 \%)$ were least likely to be responsible for domestic cooking (Table 2). However, around one fifth of the respondents (18.4\%) reported that the domestic help was in-charge of household cooking. No statistically significant differences in the perceptions of boys and girls were found.

\section{Discussion}

The present investigation reports novel findings about the adolescents' home food environment in Kolkata, India. There were four key findings: the easy accessibility of food at all times; the availability of both fresh fruits and vegetables and of nutrient-poor snacks and beverages in adolescents' homes; the enforcement of food rules during 
Table 2 Adolescents' perceptions of the home food environment (\% Always ${ }^{a}, n=1026$ )

\begin{tabular}{|c|c|c|c|c|c|c|}
\hline & $\begin{array}{l}\text { Boys } \\
\%(n) \\
\end{array}$ & $\begin{array}{l}\text { Girls } \\
\%(n) \\
\end{array}$ & $\begin{array}{l}\text { Total } \\
\%(n) \\
\end{array}$ & $x^{2}$ & $d f$ & $p$-value \\
\hline \multicolumn{7}{|l|}{ Family food rules } \\
\hline I'm allowed to buy whatever I want from fast food joints & $31.7(113)$ & $23.7(159)$ & $26.5(272)$ & 7.656 & 1 & $<0.01$ \\
\hline I can eat whatever I like at home & $62.6(223)$ & $56.7(380)$ & $58.8(603)$ & 3.367 & 1 & 0.06 \\
\hline During meal times, I'm allowed to put the TV on & $67.7(241)$ & $63.0(422)$ & $64.6(663)$ & 2.257 & 1 & 0.13 \\
\hline I'm expected to eat all the foods served even if I don't like them & $59.3(211)$ & $48.7(326)$ & $52.3(537)$ & 10.497 & 1 & $<0.01$ \\
\hline At mealtimes I have to follow certain rules & $57.9(206)$ & $55.2(370)$ & $56.1(576)$ & 0.659 & 1 & 0.42 \\
\hline \multicolumn{7}{|l|}{ Accessibility to food at home } \\
\hline Vegetables are served at dinner & $82.0(292)$ & $73.9(495)$ & $76.7(787)$ & 8.625 & 1 & $<0.01$ \\
\hline There is plenty of food at home & $86.2(307)$ & $81.8(548)$ & $83.3(855)$ & 3.307 & 1 & 0.06 \\
\hline \multicolumn{7}{|l|}{ Availability of food at home } \\
\hline Potato chips or other salty snack foods & $39.0(139)$ & $37.5(251)$ & $38.0(390)$ & 0.247 & 1 & 0.61 \\
\hline Soft drink (e.g. Coke) & $43.0(153)$ & $32.5(218)$ & $36.2(371)$ & 10.977 & 1 & $<0.01$ \\
\hline Chocolate or other lollies (sweets) & $47.2(168)$ & $46.6(312)$ & $46.8(480)$ & 0.036 & 1 & 0.84 \\
\hline Cakes/pastries/donuts/biscuits & $43.8(156)$ & $50.6(339)$ & $48.2(495)$ & 4.276 & 1 & 0.03 \\
\hline Fruits & $93.3(332)$ & $90.7(608)$ & $91.6(940)$ & 1.910 & 1 & 0.16 \\
\hline Vegetables & $94.7(337)$ & $96.3(645)$ & $95.7(982)$ & 1.460 & 1 & 0.22 \\
\hline Fruit juice & $60.1(214)$ & $53.0(355)$ & $55.5(569)$ & 4.781 & 1 & 0.02 \\
\hline \multicolumn{7}{|l|}{ Domestic cooking responsibility } \\
\hline The domestic help makes all the food at home & $21.9(78)$ & $16.6(111)$ & $18.4(189)$ & 4.416 & 1 & 0.04 \\
\hline My mother makes all the food at home & $80.1(285)$ & $80.6(540)$ & $80.4(825)$ & 0.043 & 1 & 0.83 \\
\hline My father makes all the food at home & $6.5(23)$ & $4.3(29)$ & $5.1(52)$ & 2.197 & 1 & 0.14 \\
\hline
\end{tabular}

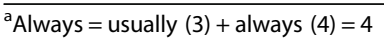

meal times; and the finding that generally adolescents' mothers acted as primary household food preparers. Since adolescents obtain $60 \%$ of their daily energy from meals sourced at home [17], these findings further reinforce the important influence of the home food environment on adolescents' food habits. In contrast to many studies conducted among adults [37, 38], the present findings represent teenagers' views of the adolescents' home food environment. Moreover, the perceptions of teenagers are expected to be more significant and valid than those of adults because the dietary intake of teenagers is more highly associated with their own perceptions than those of their parents [39].

The availability and accessibility of foods at home is an important predictor of adolescent diet quality $[9,27,40-42]$. Nearly all the respondents claimed that fruits and vegetables were always available at home. Comparable findings were reported in Project EAT (Eating Among Teens) in the US [41] and in the YEP (Youth Eating Patterns) study in Australia [42]. The availability of healthy foods in the home has been positively associated with higher diet quality among young people [9, 40, 41]. Moreover, the household availability of fruits and vegetables is negatively associated with the consumption of sugar-sweetened beverages and snacks among American adolescents [40]. In addition, vegetables were served at dinner in about three quarter of the study respondents' homes. Similarly, MacFarlane and colleagues noted that vegetables were always served for dinner in $61 \%$ of Australian homes $(n=3264)$ [42].

Nevertheless, nearly two-fifths of the adolescents reported the availability of sugar-sweetened beverages and potato chips in their homes. These findings are similar to previous reports $[19,42]$. For example, about one-third of Australian adolescents $(n=3264)$ reported that soft drink and salty snacks were usually available in their homes [42]. There is compelling evidence that the presence of sugar-sweetened beverages and energydense, nutrient-poor snacks in the home has a negative impact on the diet quality of children and adolescents $[9,22,43]$. For example, a study of American school children (aged 8-13 years) found that students who reported that carbonated beverages were available in their households were more likely to report consuming these beverages five or more times per week [44]. One implication of this finding is that Indian parents (and parents elsewhere) might implement a covert restriction strategy i.e. not having soft drink and unhealthy snacks available or accessible at home. This might be an effective way to restrict the intake of such unhealthy foods [45]. 
In addition to home food availability, family food rules may also play an important role in determining young people's food behaviours [9, 18, 42]. Approximately, three-fifths of the students in the present study were expected to follow specific food rules at meals. In contrast, only one-third of Australian adolescents $(n=3264)$ [42] and $48 \%$ of American adolescents $(n=233-237)$ [18] were expected to do the same (Both these studies used the same item ("not talking with my mouth full") as the present study). Again, in comparison to the present findings (52\%), only $35 \%$ of American adolescents were expected to consume all the foods served even if they did not like them [18]. Compulsion to consume certain foods, predominantly healthy foods, or finish meals has been associated with poor diet quality in Western cultures (e.g. the US, the UK) [20, 25] i.e. reduced intake of healthy foods (e.g. soup) [20] but greater intake of nutrient-poor snacks [25]. Perhaps, the variation in responses might be explained by the different parenting styles followed in different cultures. It is quite possible that Indian parents practiced more stringent mealtime food rules than British and American parents. Interestingly, findings from a recent qualitative investigation [27] suggest that Indian parents predominantly practice authoritative and authoritarian parenting styles similar to parents of Western cultures.

Traditionally, Indian women were entrusted with duties of household cooking $[46,47]$ and this is quite evident in the present investigation as the majority of the respondents' mothers were responsible for cooking family meals. This finding is in line with previous research in which Australian [22] and Peruvian adolescents [11] made similar observations of their mothers. Mothers have been recognised as primary dietary gatekeepers within the home environment who influence the food habits of the family members and subsequently their health status [48].

However, with the advent of globalisation, the age-old extended family structure in India has undergone a major transformation [49]. The rapid emergence of nuclear families [50] has led to increased female paid employment outside the home [51]. This might partly explain the role of domestic help in household cooking in about one-fifth of the adolescents' homes. Probably, the mothers may have used their dietary knowledge to guide their domestic help in meal preparation. However, this needs to be confirmed in further investigations. Interestingly, mothers' dietary knowledge and practices play a key role in determining their feeding practices [22]. Nevertheless, the present findings do not show how many of the $80 \%$ of mothers were employed outside home and how they managed to find time for cooking. In general, lack of time arising out of busy work schedules has been criticised for preventing cooking at home [52-54]. Moreover, whether the domestic help were equipped with appropriate declarative and procedural nutritional knowledge also remains unknown. Therefore, more research is needed to explore these issues which are vital to the evaluation of the home food environment.

\section{Strengths and limitations}

The strengths of this investigation include its large sample size, high response rate (93.6\%) and novel findings. To the best of our knowledge, this is the first and the largest survey on home food environments of adolescents in the Indian context. The study has at least three limitations. First, its cross-sectional design does not allow for the assessment of causal relationships between the variables. Future use of longitudinal or experimental designs would allow for examination of likely causal influences on adolescents' dietary practices. Second, convenience sampling was used and hence the sample may not represent the broader Indian adolescent community. Because of logistic reasons, random sampling could not be implemented in the current investigation. Third, the focus on year nine adolescents attending private English-speaking schools in Kolkata, especially given the size and diversity of the Indian population could have limited the generalisability of the findings. Future studies should include adolescents of different age groups from public and private schools in both rural and urban areas in different states of India.

\section{Implications for research and practice}

Future research on home food environments should focus on assessing the views of Indian parents about family food rules, family mealtime episodes, and home food availability. The examination of different measures including adolescents' BMI, family income, parental educational status, parents' employment status (e.g. working from home), the household availability of both healthy and unhealthy snacks and their impact on the home food environment should be considered in future research. The assessment of these variables is important for the development of nutrition promotion initiatives in home food environments. Parents may have different views of the family-environmental determinants of adolescent nutrition compared to their adolescents [39]. The views of both adolescents and parents are essential for the effective implementation of family-oriented nutrition promotion strategies. Since, mothers act as the main meal providers for their adolescents and their families, it is important to investigate their capabilities with regards to cooking and nutritional confidence, and their food acquisition and food transformation practices. In addition, there is a need to replicate this study in a matriarchal society, such as that in Kerala, India [55], where mothers may not function as the primary dietary gatekeepers. Other possible areas for exploration include the assessment of the frequency of family meals 
consumed across breakfast, lunch and dinner; role modelling by parents; and the dietary knowledge and practices of mothers and fathers in matriarchal societies. Health and educational professionals associated with adolescents and their families should be aware of the barriers and facilitators of family-environmental measures on dietary habits so that they can educate their clients accordingly. There is also scope for providing public education on the development of healthy home food environments to provide positive health benefits for adolescents and their families.

\section{Conclusion}

The present investigation provides novel insights into the home food environments of Indian adolescents. Notable findings include the easy availability and accessibility of both healthy and unhealthy foods at home, and the continuing role of mothers as the primary food gatekeepers for adolescents. These findings provide support for the development of prospective nutrition promotion strategies targeting the eating behaviours of 243 million Indian adolescents and their families.

\section{Abbreviations}

DAL: Dietary and lifestyle; DALQ: Dietary and lifestyle questionnaire; HEAG: Health Ethics Advisory Group

\author{
Acknowledgements \\ The authors would like to thank all the adolescents, teachers and school \\ principals who took part in the survey.
}

\section{Funding}

NR is supported by the Victoria-India Doctoral Scholarship. This research work received internal funding from the School of Exercise and Nutrition Sciences, Deakin University.

\section{Availability of data and materials}

The datasets used and analysed during the current study are available from the corresponding author on reasonable request.

\section{Authors' contributions}

$N R, L R$, and AW conceived the study and its original design. NR drafted the initial form and all revisions of this paper. NR collected the data and analysed the data. NR, LR, and AW reviewed and approved the final manuscript.

\section{Ethics approval and consent to participate}

This cross-sectional survey was reviewed and approved by Deakin University's Health Ethics Advisory Group (HEAG-H 187_2014). Informed written consent was received from the parents as well as the participants i.e. adolescents.

\section{Consent for publication \\ Not applicable}

\section{Competing interests}

The authors declare that they have no competing interests.

\section{Publisher's Note}

Springer Nature remains neutral with regard to jurisdictional claims in published maps and institutional affiliations.
Received: 12 July 2017 Accepted: 16 January 2018

Published online: 22 January 2018

\section{References}

1. Shukla N, Shukla M, Agarwal D, Shukla R, Sidhu H. Prevalence of overweight and obesity among adolescents in India: a systematic review. Int J Curr Res Rev. 2016:8:21-5.

2. Ranjani H, Mehreen T, Pradeepa R, Anjana RM, Garg R, Anand K, Mohan V. Epidemiology of childhood overweight \& obesity in India: a systematic review. Indian J Med Res. 2016;143:160-74.

3. National Institute of Nutrition. Dietary guidelines for Indians: a manual, 2nd edn. Hyderabad: National Institute of Nutrition; 2010.

4. Shaikh NI, Patil SS, Halli S, Ramakrishnan U, Cunningham SA. Going global: Indian adolescents' eating patterns. Public Health Nutr. 2016;19:2799-807.

5. Harrell M, Medina J, Greene-Cramer B, Sharma SV, Arora M, Nazar G. Understanding eating behaviors of new Dehli's youth. J Appl Res Child. 2015;6:1-16.

6. Adolescent Health Academy: Adolescent Health. http://ahaiap.org/ (2014). Accessed 13 May 2016.

7. UNICEF. The state of the World's children 2011: adolescence- an age of opportunity. New York: UNICEF; 2011.

8. Croll JK, Neumark-Sztainer D, Story M. Healthy eating: what does it mean to adolescents? J Nutr Educ. 2001;33:193-8.

9. Pearson N, Griffiths P, Biddle SJ, Johnston JP, Haycraft E. Individual, behavioural and home environmental factors associated with eating behaviours in young adolescents. Appetite. 2017:112:35-43.

10. Story M, Neumark-Sztainer D, French S. Individual and environmental influences on adolescent eating behaviors. J Am Diet Assoc. 2002;102:40-51.

11. Banna JC, Buchthal OV, Delormier T, Creed-Kanashiro HM, Penny ME. Influences on eating: a qualitative study of adolescents in a periurban area in lima, Peru. BMC Public Health. 2016; https://doi.org/10.1186/s12889-0162724-7.

12. Pearson N, Ball K, Crawford D. Predictors of changes in adolescents' consumption of fruits, vegetables and energy-dense snacks. Br J Nutr. 2011; 105:795-803.

13. Neumark-Sztainer D, Larson NI, Fulkerson JA, Eisenberg ME, Story M. Family meals and adolescents: what have we learned from project EAT (eating among teens)? Public Health Nutr. 2010;13:1113-21.

14. Resnick MD, Bearman PS, Blum RW, Bauman KE, Harris KM, Jones J, Tabor J, Beuhring T, Sieving RE, Shew M. Protecting adolescents from harm: Findings from the national longitudinal study on adolescent health. J Am Med Assoc 1997; 278:823-832

15. Eisenberg ME, Olson RE, Neumark-Sztainer $D$, Story $M$, Bearinger LH. Correlations between family meals and psychosocial well-being among adolescents. Arch Pediatr Adolesc Med. 2004;158:792-6.

16. Woodruff SJ, Hanning RM. A review of family meal influence on adolescents' dietary intake. Can J Diet Pract Res 2008; 69:14-22.

17. Adair LS, Popkin BM. Are child eating patterns being transformed globally? Obesity. 2005;13:1281-99.

18. Neumark-Sztainer D, Story M, Ackard D, Moe J, Perry C. Family meals among adolescents: findings from a pilot study. J Nutr Educ. 2000;32:335-40.

19. Utter J, Scragg R, Schaaf D, Mhurchu CN. Relationships between frequency of family meals, BMI and nutritional aspects of the home food environment among New Zealand adolescents. Int J Behav Nutr Phys Act. 2008; https:// doi.org/10.1186/1479-5868-5-50.

20. Galloway AT, Fiorito LM, Francis LA, Birch LL. 'Finish your soup': counterproductive effects of pressuring children to eat on intake and affect. Appetite. 2006;46:318-23.

21. Young EM, Fors SW, Hayes DM. Associations between perceived parent behaviors and middle school student fruit and vegetable consumption. J Nutr Educ and Behav. 2004;36:2-12

22. Campbell KJ, Crawford DA, Salmon J, Carver A, Garnett SP, Baur LA. Associations between the home food environment and obesity-promoting eating behaviors in adolescence. Obesity. 2007;15:719-30.

23. Gillman MW, Rifas-Shiman SL, Frazier AL, Rockett HR, Camargo CA Jr, Field $A E$, Berkey CS, Colditz GA. Family dinner and diet quality among older children and adolescents. Arch Fam Med. 2000;9:235-40.

24. Neumark-Sztainer D, Hannan PJ, Story M, Croll J, Perry C. Family meal patterns: associations with sociodemographic characteristics and improved dietary intake among adolescents. J Am Diet Assoc. 2003;103:317-22. 
25. Brown R, Ogden J. Children's eating attitudes and behaviour: a study of the modelling and control theories of parental influence. Health Educ Res. 2004; 19:261-71.

26. Loth KA, RF ML, Fulkerson JA, Crow S, Neumark-Sztainer D. Food-related parenting practices and adolescent weight status: a population-based study. Pediatrics. 2013;131:e1443-50.

27. Rathi N, Riddell L, Worsley A. What influences urban Indian secondary school students' food consumption?-a qualitative study. Appetite. 2016;105: 790-7.

28. Cooke LJ, Wardle J. Age and gender differences in children's food preferences. Br J Nutr. 2005;93:741-6.

29. Beardsworth A, Bryman A, Keil T, Goode J, Haslam C, Lancashire E. Women, men and food: the significance of gender for nutritional attitudes and choices. Br Food J. 2002;104:470-91.

30. Rathi N, Riddell L, Worsley A. Secondary school students' views of food and nutrition education in Kolkata, India. Health Educ. 2017;117:310-22.

31. Rathi N, Riddell L, Worsley A. The role of Indian school canteens in nutrition promotion. Br Food J. 2018;120:196-209.

32. Rathi N, Riddell L, Worsley A. Food consumption patterns of adolescents aged 14-16 years in Kolkata, India. Nutr J. 2017; https://doi.org/10.1186/ s12937-017-0272-3.

33. Subashini K, Sunmathi D, Nalinakumari S. Prevalence of overweight and obesity among private and government school children. Int J adv. Eng Sci. 2015;4:48-66.

34. Kingdon GG. The progress of school education in India. Oxf Rev Econ Pol. 2007;23:168-95.

35. Fulkerson JA, Neumark-Sztainer D, Story M. Adolescent and parent views of family meals. J Am Diet Assoc. 2006;106:526-32.

36. Neumark-Sztainer D, Wall M, Perry C, Story M. Correlates of fruit and vegetable intake among adolescents: findings from project EAT. Prev Med. 2003;37:198-208

37. Fulkerson JA, Kubik MY, Rydell S, Boutelle KN, Garwick A, Story M, NeumarkSztainer D, Dudovitz B. Focus groups with working parents of school-aged children: What's needed to improve family meals? J Nutr Educ Behav. 2011; 43:189-93.

38. Cluskey M, Edlefsen M, Olson B, Reicks M, Auld G, Bock MA, Boushey CJ, Bruhn C, Goldberg D, Misner S. At-home and away-from-home eating patterns influencing preadolescents' intake of calcium-rich food as perceived by Asian, Hispanic and non-Hispanic white parents. J Nutr Educ Behav. 2008:40:72-9.

39. Van Assema P, Glanz K, Martens M, Brug J. Differences Between parents' and adolescents' perceptions of family food rules and availability. J Nutr Educ Behav 2007; 39:84-89.

40. Loth KA, MacLehose RF, Larson N, Berge JM, Neumark-Sztainer D. Food availability, modeling and restriction: how are these different aspects of the family eating environment related to adolescent dietary intake? Appetite. 2016;96:80-6.

41. Hanson NI, Neumark-Sztainer D, Eisenberg ME, Story M, Wall M. Associations between parental report of the home food environment and adolescent intakes of fruits, vegetables and dairy foods. Public Health Nutr. 2005;8:77-85.

42. MacFarlane A, Crawford D, Ball K, Savige G, Worsley A. Adolescent home food environments and socioeconomic position. Asia Pac J Clin Nutr 2007; 16:748-755.

43. Couch SC, Glanz K, Zhou C, Sallis JF, Saelens BE. Home food environment in relation to children's diet quality and weight status. J Acad Nutr Diet. 2014; doi:114:1569-1579. e1561.

44. Grimm GC, Harnack L, Story M. Factors associated with soft drink consumption in school-aged children. J Am Diet Assoc. 2004;104:1244-9.

45. Ogden J, Reynolds R, Smith A. Expanding the concept of parental control: a role for overt and covert control in children's snacking behaviour? Appetite. 2006:47:100-6.

46. Bahadur A, Dhawan N. Social value of parents and children in joint and nuclear families. J Indian Acad. Appl Psychol. 2008;34:74-80.

47. Srinivas T. As mother made it' : the cosmopolitan Indian family, authentic food and the constructuion of cultural utopia. Int J Sociol Fam. 2006;32: 191-221.

48. Reid M, Worsley A, Mavondo F. The obesogenic household: factors influencing dietary gatekeeper satisfaction with family diet. Psychol Market. 2015;32:544-57.

49. Sooryamoorthy R. The Indian family: needs for a revisit. J Comp Fam Stud. 2012;43:1-9.
50. Niranjan S, Nair S, Roy T. A socio-demographic analysis of the size and structure of the family in India. J Comp Fam Stud. 2005;36:623-51.

51. Ministry of Labour \& Employment: About women labour. 2014. http:// labour.gov.in/employment-publications. Accessed 31 Aug 2016.

52. Lichtenstein AH, Ludwig DS. Bring back home economics education. J Am Med Assoc. 2010;303:1857-8.

53. Caraher M, Dixon P, Lang T, Carr-Hill R. The state of cooking in England: the relationship of cooking skills to food choice. Br Food J. 1999;101:590-609.

54. Slater J, Hinds A. University student perceptions of home economics: food and nutrition education. Int. J Home Econ. 2014;7:68-80.

55. Chacko E. Marriage, development, and the status of women in Kerala, India. Gend Dev. 2003;11:52-9.

\section{Submit your next manuscript to BioMed Central and we will help you at every step:}

- We accept pre-submission inquiries

- Our selector tool helps you to find the most relevant journal

- We provide round the clock customer support

- Convenient online submission

- Thorough peer review

- Inclusion in PubMed and all major indexing services

- Maximum visibility for your research

Submit your manuscript at www.biomedcentral.com/submit
) Biomed Central 